\title{
Radar remote sensing from space for surface deformation analysis: present and future opportunities from the new SAR sensor generation
}

\author{
Eugenio Sansosti $\cdot$ Michele Manunta $\cdot$ Francesco Casu $\cdot$ Manuela Bonano $\cdot$ \\ Chandrakanta Ojha $\cdot$ Maria Marsella $\cdot$ Riccardo Lanari
}

Received: 15 April 2015/ Accepted: 4 May 2015/Published online: 26 May 2015

(C) The Author(s) 2015. This article is published with open access at Springerlink.com

\begin{abstract}
This paper discusses, through two selected case studies based on real data, how the availability of the new generation of Synthetic Aperture Radar (SAR) sensors, characterized by reduced revisiting time and improved spatial resolution or coverage, is impacting the exploitation of Differential SAR Interferometry (DInSAR) techniques for the detection and monitoring of deformation phenomena. The presented analysis is carried out using X-band data of the COSMO-SkyMed constellation satellites, as well as C-band data acquired by the Sentinel-1A sensor; furthermore, we compare the achieved results to those based on first-generation ERS-1/2 and ENVISAT satellite data. The first case study shows how the COSMO-SkyMed $\mathrm{X}$-band SAR systems open new opportunities for the detection and monitoring of deformation phenomena at the scale of a single building, even when they are characterized by a rather fast dynamic. The second experiment is based on the Sentinel-1A DInSAR measurements and permits us to envisage new scenarios for deformation analysis of very wide areas. The final discussion is devoted to summarise the lessons learned through the presented case studies and to identify the main future actions needed for a full exploitation of the surface deformation measurement capability provided by the new generation of SAR sensor.
\end{abstract}

Peer reviewed version of the paper presented at conference on Geodesy and Geomatics held at Accademia Nazionale dei Lincei in Rome on June 3, 2014.

E. Sansosti $(\bowtie) \cdot$ M. Manunta $\cdot$ F. Casu $\cdot$ M. Bonano

C. Ojha $\cdot$ R. Lanari

CNR-IREA, Via Diocleziano, 328, 80124 Naples, Italy

e-mail: sansosti.e@irea.cnr.it

C. Ojha · M. Marsella

Sapienza Università di Roma, Via Eudossiana, 18, 00184 Rome, Italy
Keywords Ground deformation - Remote Sensing · Synthetic Aperture Radar (SAR) · DInSAR · Urban monitoring $\cdot$ Wide area monitoring

\section{Introduction}

The investigation of deformation phenomena affecting the Earth surface is a key element for the analysis of natural events such as earthquakes (Okada 1985; Chinnery 1961), volcano unrest phases (Mogi 1958) and landslides (Farrell 1972). Furthermore, it can be very important for investigating the impact of anthropogenic actions such as ground water exploitation (Hsieh 1996), mining and tunnelling activities (Shixiang and Dade 2004; O'Reilly and New 1982), oil and gas extraction (Yerkes and Castle 1969), as well as gas capture and storage (Orr 2009).

In the ground deformation investigation scenario, a central role is played by the use of Synthetic Aperture Radar (SAR) systems, peculiar radar sensors capable of providing high-resolution microwave images. Due to the larger wavelength compared to visible and infrared radiation, microwaves (wavelength between $1 \mathrm{~cm}$ and $1 \mathrm{~m}$ ) exhibit the important property of penetrating clouds, fog, and possible ash or powder coverage (for example, in case of an erupting volcano or a collapsed building). This important property provides an imaging capability in any weather condition or environment, although some atmospheric disturbances can affect both the amplitude and, more importantly, the phase of SAR images.

Ground deformations are estimated using the Differential Synthetic Aperture Radar Interferometry (DInSAR) technique, which is based on the exploitation of microwave image pairs (Franceschetti and Lanari 1999); this technique is particularly powerful for its capability to generate 
spatially dense deformation maps of large areas, with centimetre to millimetre accuracy (Gabriel et al. 1989; Massonnet and Feigl 1998; Burgmann et al. 2000).

More specifically, the DInSAR technique exploits the phase difference (interferogram) between SAR image pairs acquired at different times (whose separation is referred to as temporal baseline) but with the same illumination geometry and from sufficiently close flight tracks (whose separation is referred to as spatial baseline) (Franceschetti and Lanari 1999). To separate the deformation contribution from the topographic one, the DInSAR technique analyses the so-called differential interferograms, which are generated by compensating interferograms with their topography-related phase component, usually computed by means of an external Digital Elevation Model (DEM) (Gabriel et al. 1989; Massonnet and Feigl 1998; Franceschetti and Lanari 1999; Burgmann et al. 2000). We also note that the DInSAR technique allows estimating the surface displacements occurred between two observations in terms of their component along the radar line of sight (LOS) and properly works in areas not significantly affected by the interferometric noise effects associated with the loss of coherence between the two observations (Zebker and Villasenor 1992); this noise is mainly related to the random nature of target response and to the fact that data are acquired at different times (temporal decorrelation) and from different positions in space (spatial decorrelation).

Originally, the DInSAR methodology has been applied to analyse single deformation episodes (Massonnet et al. 1993; Peltzer and Rosen 1995; Rignot 1998); however, especially thanks to the availability of large C-band data stacks, collected between 1992 and 2010 from the ERS-1/2 to ENVISAT ESA SAR sensors, the interest of the scientific community has significantly moved towards the study of the temporal evolution of the detected deformations. This is possible through the exploitation of advanced
DInSAR techniques (Sansosti et al. 2010), which properly combine a set of multi-temporal differential interferograms relevant to the area of interest, to compute the deformation time series of the observed area.

The advanced DInSAR techniques are usually grouped into two main categories:

- Persistent scatterer (PS) methods (Ferretti et al. 2001; Werner et al. 2003), which do not impose any constraint on the temporal and spatial baselines of the exploited multi-temporal differential interferograms and are mostly focused on investigating single point targets, and

- Small baseline (SB) techniques (Berardino et al. 2002; Mora et al. 2003; Lanari et al. 2004) that, on the contrary, impose constraints on the maximum temporal and spatial baselines, but allows us to analyse distributed targets too.

The space-borne SAR scenario is already characterized by the availability of a huge dataset acquired during the last 25 years (see Fig. 1), including the above-mentioned longterm C-band ERS-1/2 and ENVISAT archives in addition to the C-band RADARSAT- $1 / 2$ data sequences and those provided by the L-band JERS-1 and ALOS-1 systems.

However, although the advanced DInSAR techniques have drastically improved the accuracy of ground deformation estimation (Casu et al. 2006; Bonano et al. 2013), their applicability during emergency response phases, or in presence of rapidly varying displacements, has shown to be somehow limited, mostly because of the rather too long (monthly) revisit time of these SAR sensors. In this context, a major step forward has been represented by the advent of second-generation SAR systems, which is in part fully operational, as for the X-band SAR sensors of the COSMO-SkyMed (CSK) (Covello et al. 2010) and TerraSAR-X (TSX) (Werninhaus and Buckreuss 2010) constellations.

Fig. 1 Space-borne SAR systems evolution

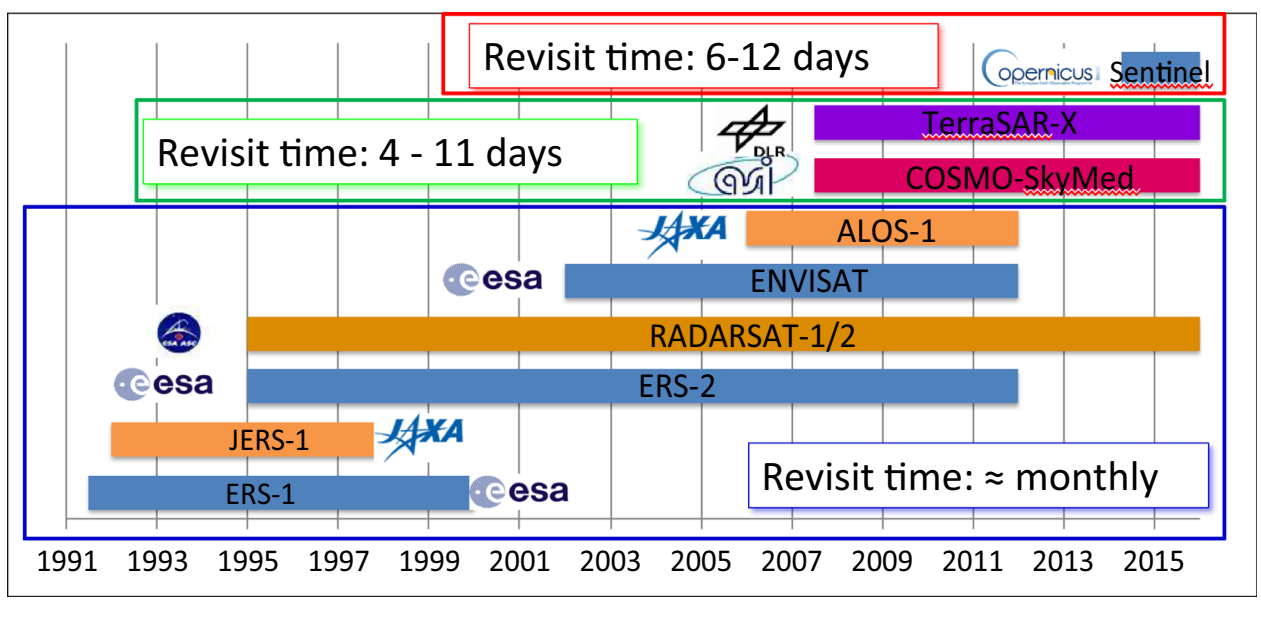

Time [years] 
Moreover, a massive (yet increasing) data flow is expected from the SENTINEL-1A (S-1A) satellite (Torres et al. 2012) recently launched (April 2014) within the framework of the European Union COPERNICUS (formerly GMES) programme (http://www.copernicus.eu). This satellite will also be paired in 2016 with the SENTINEL-1B (S-1B) twin system, in such a way to halve the system revisit time (from 12 to 6 days). Accordingly, new large data archives relevant to large areas on Earth will be soon available; they will be acquired with the Terrain Observation with Progressive Scan (TOPS) mode, specifically devoted to DInSAR applications (Torres et al. 2012), and in a free and open access data policy.

Although these new generation SAR sensors are characterized by different operating frequencies, spatial resolutions and coverages, they all exhibit a common characteristic: a reduced revisit time, which can be as short as 4-8 days for the CSK constellation case (Sansosti et al. 2014). Figure 1 summarises the space-borne SAR systems evolution.

In this work, we discuss, through two selected case studies based on real data, how the availability of secondgeneration SAR sensors is impacting the present DInSAR scenario. First, we investigate the results based on an $\mathrm{X}$-band image sequence acquired by CSK constellation and processed through the advanced SB DInSAR approach referred to as Small BAseline Subset (SBAS) algorithm (Berardino et al. 2002; Mora et al. 2003; Lanari et al. 2004); in this case, we focus on the Roma (Italy) urban area to show the capability of the CSK constellation to map small-scale deformation phenomena affecting buildings and infrastructures. Moreover, to highlight the achieved improvements, the obtained CSK results are compared to those obtained through equivalent DInSAR processing of ERS-1/2 and ENVISAT data (Pepe et al. 2005; Bonano et al. 2012).

The second case study is devoted to the exploitation of the S-1A DInSAR results based on data acquired over the Napoli Bay area during the first months of operation. In this case, we compare the deformation mapping capability of S-1A and ERS/ENVISAT interferograms (processed at similar spatial resolutions) in terms of achieved interferometric coherence and area coverage and show the performance improvement achieved by the S-1A system.

Finally, we summarise the lessons learned through the presented case studies and identify some future key actions needed for a full exploitation of the surface deformation measurement capability provided by the new generation of SAR sensors.

\section{High-resolution deformation time series analysis: the city of Roma (Italy) case study}

The scope of this section is to show both the qualitative and quantitative improvements achieved by the CSK (X-band)derived DInSAR products (i.e., mean deformation velocity maps and time series) with respect to the corresponding ERS-1/2 and ENVISAT (C-band) ones. The comparative analysis aims at understanding the impact of the improved spatial resolution and revisit time of the CSK data on the investigation of deformation phenomena at the scale of single buildings and infrastructures. To this end, we have chosen as a suitable study area the densely inhabited city of Roma (Italy), where large SAR data archives, acquired from both the C- and X-band SAR sensors, are available. To carry out our analysis, we apply the extended fullresolution SBAS-DInSAR technique (Lanari et al. 2004; Bonano et al. 2012) to the two SAR datasets. In particular, the comparison is performed by using a C-band set of 91 ERS-1/2 and 40 ENVISAT SAR images, acquired over descending orbits between 1992 and 2010, and an X-band sequence of 40 CSK SAR images, collected over ascending orbits between 2010 and 2012. From the above-mentioned images, 352 and 124 differential SAR interferograms have been generated by imposing maximum spatial baseline constraints of $400 \mathrm{~m}$ and $500 \mathrm{~m}$ for the ERS/ENVISAT and the CSK datasets, respectively. For the interferogram generation, precise satellite orbital information and the three-arcsec SRTM DEM of the study zone have been used (Farr et al. 2007).

Preliminary considerations related to the welldocumented surface displacements occurred during the last 20 years in correspondence to the urban area of Roma are first carried out. In Fig. 2, the full-resolution SBAS-DInSAR mean deformation velocity map, superimposed on an optical image of the investigated zone and relevant to the 1992-2010 ERS/ENVISAT time series, is shown; each coloured point represents a coherent pixel (measuring point), while the colour accounts for the mean deformation velocity. As already known (Manunta et al. 2008; Stramondo et al. 2008; Zeni et al. 2011), the most significant deformation phenomena are located along the alluvial plain bordering the Tevere and Aniene rivers and are characterized by an almost linear subsidence trend of about $1 \mathrm{~cm} /$ year (even more, in some zones); they are mainly associated with soil compaction. The soil consolidation is due to the high compressibility level and to the overloads of newly constructed buildings over this area. Nevertheless, possible variations or irregularities of the soils com- 


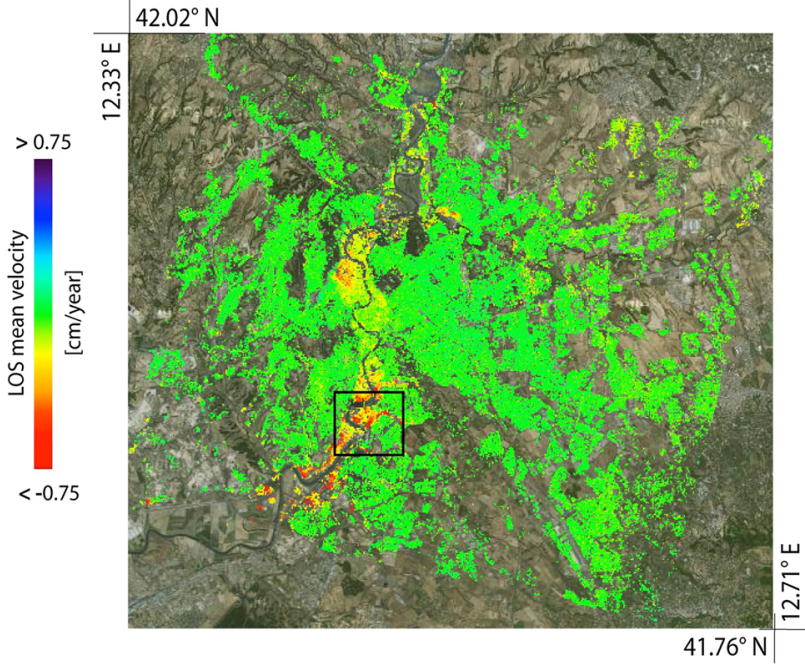

Fig. 2 Full-resolution SBAS-DInSAR mean deformation velocity map, superimposed on an optical image of the city of Roma and relevant to the 1992-2010 ERS/ENVISAT data archive. The black box indicates the test area relevant to Viale Marconi

pounding the alluvial deposits (Manunta et al. 2008), as well as local instabilities due to structural or foundation weaknesses (Arangio et al. 2013), should be also taken into account to have a clear picture of the temporal evolution of the deformation affecting each single structure, or even a part of it with respect to the rest. The availability of both Cand X-band SAR data archives allows us to show that moving from ERS/ENVISAT to CSK data is beneficial for increasing the spatial density of coherent pixels (measuring points) within the deformation maps. In particular, by comparing the ERS/ENVISAT and CSK results (Fig. 3), the significant density improvement attained through the $\mathrm{X}$-band data analysis is clearly visible. This pixel density increase is particularly relevant because it allows most of the manmade structures located within the urban area to be mapped. Note also that such a density improvement is also related to the shorter time span ( $\sim 2$ years) covered by CSK data with respect to the C-band one ( $\sim 20$ years): this significantly reduces the temporal decorrelation effect in the generated interferograms (Zebker and Villasenor 1992). Furthermore, thanks to the higher spatial resolution of CSK data ( $\sim 3 \mathrm{~m}$ for the stripmap mode, but potentially down to $\sim 1 \mathrm{~m}$ for the spotlight mode case), it is possible to extend the deformation analysis also on portions of the identified structures, thus potentially detecting intra-building differential movements, which is particularly important in the framework of collapse prevention.

For better clarifying the last point, we focus on a selected building located in the Viale Marconi area (see white circle in Fig. 3), where a subsidence deformation pattern with a rate up to $1 \mathrm{~cm} /$ year is clearly noticeable. In particular, by analysing the zoomed views of the ERS/ENVISAT and
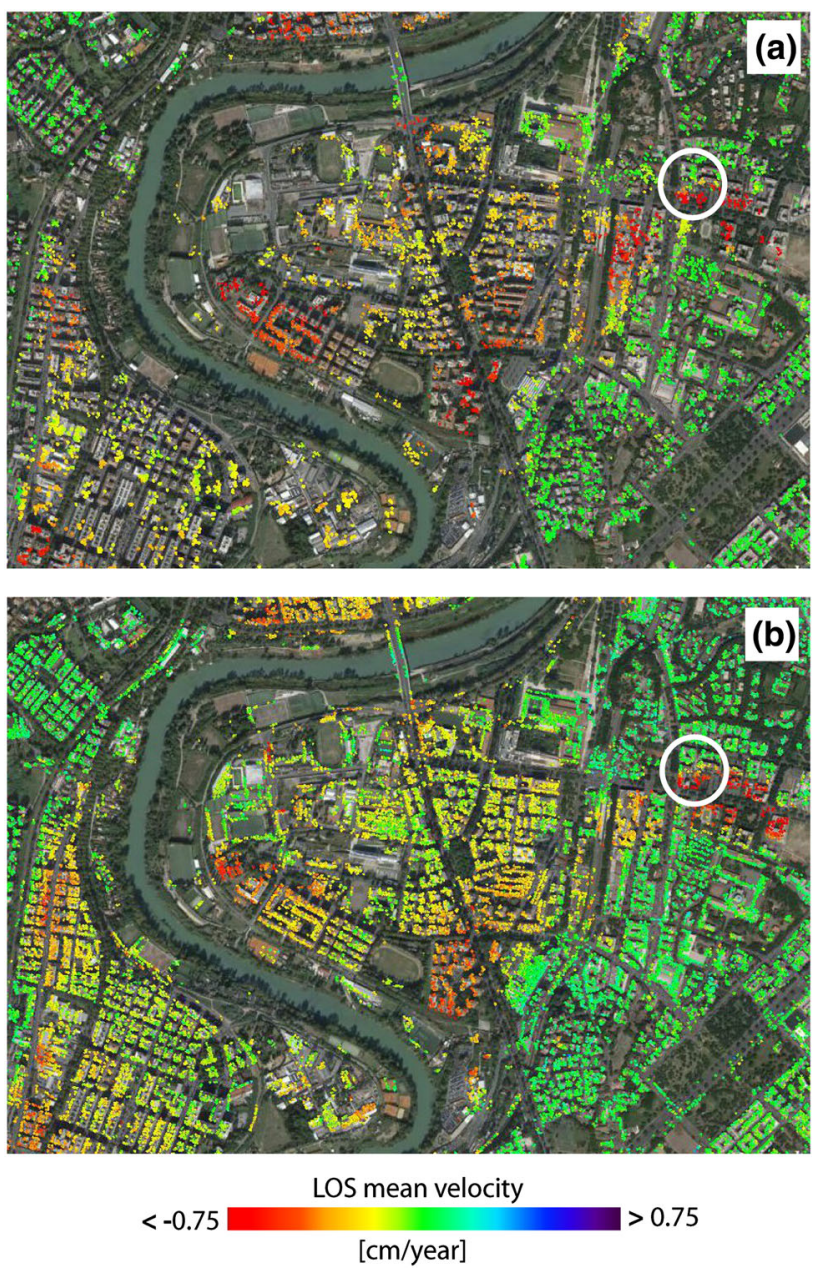

Fig. 3 Comparison between the ERS/ENVISAT and CSK SBASDInSAR results relevant to the selected area identified by the black box in Fig. 2. a Zoomed view of the full-resolution SBAS-DInSAR results achieved through the 1992-2010 ERS/ENVISAT SAR data archive for the investigated area. b Zoomed view of the fullresolution SBAS-DInSAR results achieved through the 2010-2012 CSK SAR data archive for the selected area. The white circles indicate the position of the investigated building

CSK deformation velocity maps (Fig. 4a, b), it is clear that the improved performances of the new generation sensors drastically increase the density of the measured coherent pixels (coloured markers in Fig. 4). This allows mapping the spatial distribution of the occurring displacements with greater detail, highlighting also possible intra-building movements, as shown in Fig. $4 \mathrm{~b}$, where a differential movement affecting the West facade of the building is clearly visible.

Focusing on the time evolution of the deformation phenomena, it is worth pointing out the main advantages achieved by the much shorter CSK revisit times compared to ERS/ENVISAT one, which is particularly relevant for analysing temporal fast-varying or non-linear deformation signals. Indeed, with a temporal sampling of a few days, it 


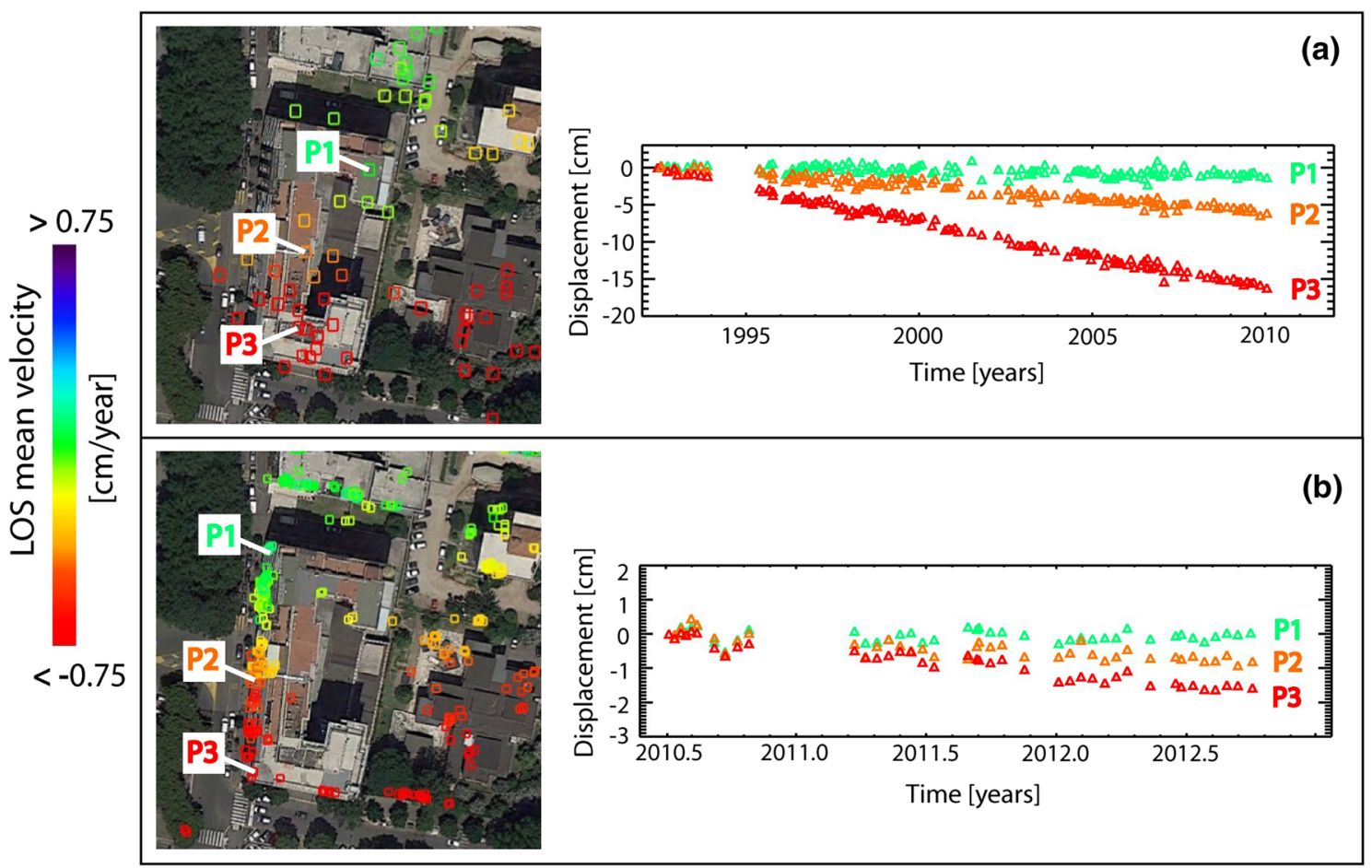

Fig. 4 Comparison between ERS/ENVISAT and CSK full-resolution SBAS-DInSAR results relevant to a building located in Viale Marconi area (see Fig. 3 for its location). a Zoomed view of the ERS/ ENVISAT SBAS-DInSAR velocity map, superimposed on an optical image of the investigated building (left), and corresponding time

becomes possible to collect a very large number of CSK images in a short interval (up to 80 images/year in the best case), whereas only 11 images/year (at most) were available for the ERS or the ENVISAT satellites due to their monthly revisit frequency. Furthermore, the high temporal sampling rate of CSK time series is particularly suitable to carry out deformation analyses over very short time intervals, allowing us to collect a number of SAR scenes (at least 25/30) sufficient to guarantee the typical performances of the SBAS-DInSAR approach in terms of displacement time series accuracy (Casu et al. 2006; Bonano et al. 2013) even on short time periods. To better investigate this characteristic, we compare the ERS/ENVISAT and CSK time series of three selected points located in correspondence to the North-South section of a building affected by differential movements, see Fig. 4. It is worth noting that, although the available CSK dataset has been acquired within a very short time span of 2.5 years only, a detailed temporal SBAS-DInSAR analysis is still doable. Indeed, the plots in Fig. 4 clearly show the general agreement between ERS/ENVISAT and CSK time series, in terms of the linear deformation trend relevant to their different observation periods, also confirmed by their similar deformation velocity rates of about $7 \mathrm{~mm} / \mathrm{year}$. Moreover, despite the limited number of CSK scenes (i.e., series relevant to three pixels labelled as $\mathrm{P} 1, \mathrm{P} 2$ and $\mathrm{P} 3$, respectively (right). b Zoomed view of the CSK SBAS-DInSAR results (left), and related deformation time series for three pixels labelled as P1, P2 and $\mathrm{P} 3$, respectively (right)

only 40 images were available for the Roma case, instead of the 200 scenes that could have been potentially collected within the time interval), it is anyway possible to achieve a better temporal sampling with respect to the first-generation case, in which, for instance, at most 25 images would have been available in the same temporal interval if ENVISAT was still in operation. The reduced temporal sampling is strategic to effectively follow the evolution of the displacements also in case of deformation phenomena occurring during short time spans. Moreover, a better temporal sampling is also beneficial when statistical spatiotemporal filtering of atmospheric effects is to be performed (Ferretti et al. 2001; Berardino et al. 2002).

\section{Wide area surface deformation analysis: the case study of Napoli Bay (Italy)}

In this section, we investigate the capability of the S-1A system to carry out DInSAR analyses over wide areas. First, we remark that the S-1A data are acquired on land by exploiting the TOPS mode (Torres et al. 2012) that is particularly effective for DInSAR and advanced DInSAR applications. Indeed, this mode allows the S-1A sensor to generate C-band SAR images with spatial resolutions 
(azimuth resolution around $15 \mathrm{~m}$, range resolution around 2.5) comparable with those achievable by the ERS-1/2 and ENVISAT SAR systems (for ERS and ENVISAT: azimuth resolution around $4.5 \mathrm{~m}$, range resolution around $8 \mathrm{~m}$ ), but with a much wider swath. Indeed, S-1A reaches $280 \mathrm{~km}$ of swath which is significantly larger than the $100 \mathrm{~km}$ of the ERS and ENVISAT stripmap modes. We also note that, while ENVISAT wide swath mode (Scansar) showed a coverage comparable to $\mathrm{S}-1 \mathrm{~A}$, this was not suitable for routinely application of DInSAR techniques due to the lack of burst synchronisation (Guccione 2006). To highlight the spatial coverage differences, in Fig. 5, we compare the amplitude of a ENVISAT stripmap image of the Napoli Bay area (Italy), with the corresponding S-1A one; the improvement achieved by the S-1A system is evident.

Moreover, the small orbital tube of the S-1A baselines and the significantly reduced revisit time of 12 days open new possibilities to systematically generate highly coherent interferometric products of very wide areas, see Fig. 6. High coherence implies a drastic reduction of the decorrelation noise and, therefore, an increase of the phase measurement precision for interferometric applications.

To better highlight the impact of the shorter S-1A revisit time, we compare ERS or ENVISAT differential

Fig. 5 Comparison between the spatial coverage of SENTINEL$1 \mathrm{~A}$ and ENVISAT systems. The example is relevant to the Napoli Bay area (Italy)
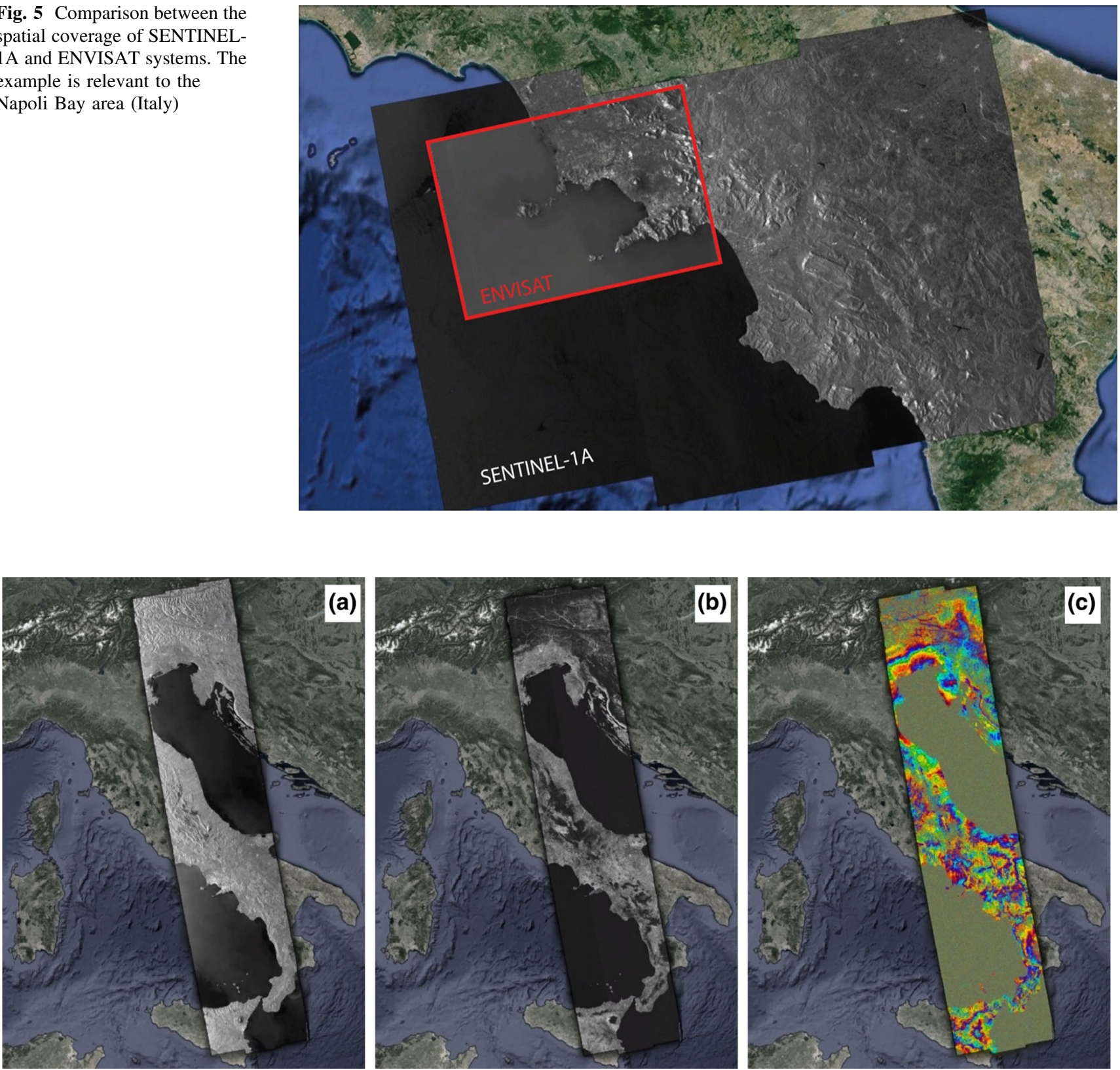

Fig. 6 SENTINEL-1A wide area processing. a amplitude image; $\mathbf{b}$ coherence; $\mathbf{c}$ interferogram 
interferograms spanning 35 days with S-1A ones spanning 12 days. The achieved improvements in terms of coherence are evident in the S-1A interferograms. As an example, in Fig. 7, two ENVISAT (Fig. 7a-d) and two S-1A (Fig. 7e-h) interferograms are shown, as well as the corresponding spatial coherence maps. All the selected interferometric pairs are characterized by very short spatial baseline
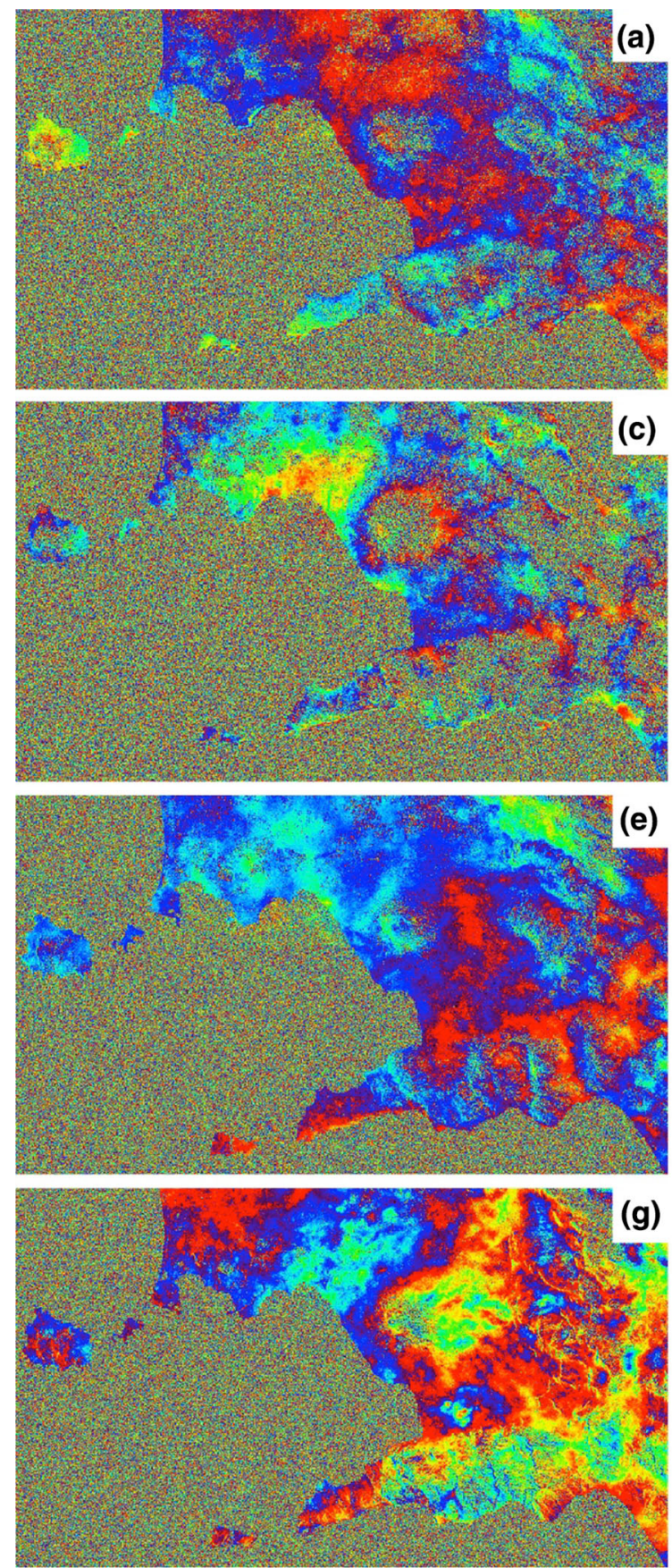

Fig. 7 Comparison between ENVISAT and SENTINEL-1A interferometric capabilities. a-d ENVISAT interferograms (left) and spatial coherence maps (right) relevant to two data pairs characterized by less than $50 \mathrm{~m}$ of spatial baseline and 35 days of temporal
( $<50 \mathrm{~m}$ ), while the temporal separation is 35 and 12 days for the ENVISAT and the S-1A pairs, respectively.

All the above findings clearly pushes towards the direction to properly configure the forthcoming twin sensor SENTINEL-1B to achieve a 6-day revisit time, thus further improving the coherence of the generated multi-temporal differential interferograms.
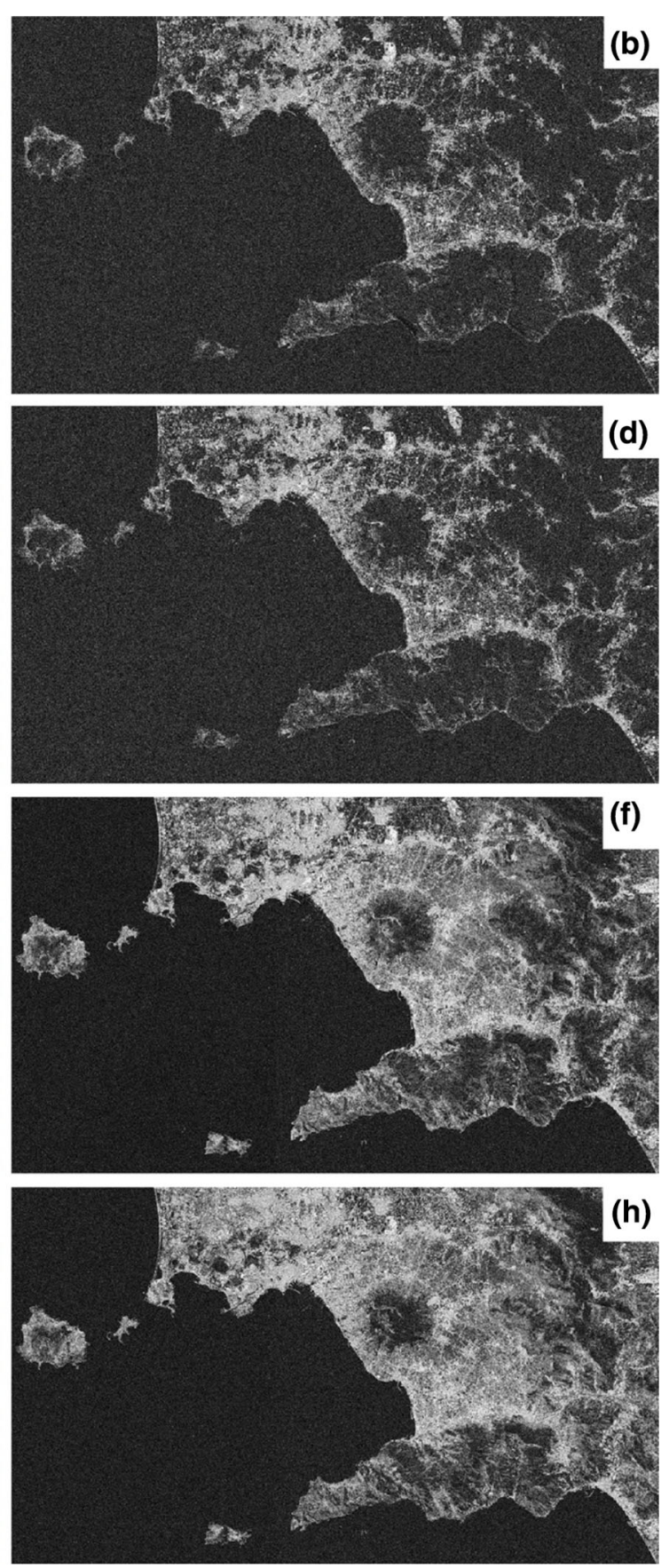

separation. $\mathbf{e}-\mathbf{h}$ SENTINEL-1A interferograms (left) and spatial coherence maps (right) relevant to two data pairs characterized by $<50 \mathrm{~m}$ of spatial baseline and 12 days of temporal separation 


\section{Conclusion}

Through two selected case studies, based on the use of real data acquired by the COSMO-SkyMed constellation and the SENTINEL-1A sensor, we have discussed how the use of second-generation SAR sensors is impacting (and somehow changing) the role of Earth Observation in research and monitoring activities relevant to surface deformation phenomena. Key factors of these sensors are the reduced revisiting time and improved spatial resolution or coverage.

One of the most important results arising from the use of second-generation SAR data is that phenomena can be detected earlier and can be studied with better temporal details with respect to the first-generation SAR systems. These characteristics open new possibilities for the operational use of such techniques as a monitoring tool in early warning scenarios.

The new generation of X-band SAR sensors allows ground deformation to be captured with a great level of spatial detail; the capability to detect and monitor the temporal evolution of displacements affecting single buildings, or even the intra-building ones, demonstrates the great potentiality for geotechnical and structural engineering analyses.

On the other hand, the presented results obtained by exploiting SENTINEL-1A data permit to envisage new scenarios for very large area deformation analysis. The reduced revisit time of this system, together with the limited spatial baselines and the wide area coverage (the latter ensured by the operating TOPS mode), represents already a breakthrough. Indeed, it is already clear that the exploitation of the free and open access data archives collected by the SENTINEL-1A system (to be paired during 2016 with the SENTINEL-1B twin system) open new research and monitoring perspectives to investigate Earth surface deformation dynamics at the continental scale.

While the presented case studies provide excellent examples of the present and future opportunities offered by the second-generation SAR sensors for the study of ground deformation, they also highlight some limitations that need to be promptly mitigated for a full exploitation of the new sensors capabilities.

A major drawback (affecting mainly DInSAR time series analyses) is represented by the great increase of computational effort in terms of both amount of data to be handled/ stored and required CPU time. This characteristic forces to perform an optimization of existing algorithms; a possible choice is the implementation of algorithm portability to distributed hardware architectures (Lee et al. 2011; Sadashiv and Kumar 2011). In this scenario, a key role can be played by the Cloud Computing technologies that are well established within the Information and Communication
Technologies (ICT) community (Badger et al. 2012; Rosen et al. 2012), but whose exploitation in the SAR and, particularly, DInSAR data processing field is still at an early stage (Casu et al. 2014). Indeed, by considering the already existing large SAR data archives and in view of the abovementioned huge data flow coming from the SENTINEL-1 constellation, it is clear that in-house facilities (even those based on grid architecture) can be a bottleneck due to their limited resources; this is particularly the case if the provisioning of multi-user services, allowing to process SAR data through advanced DInSAR methods and to access to the achieved results, is in order. Accordingly, Cloud Computing Environments may represent a solution to achieve both large storage and high computing performance capabilities. To this end, it is clear that proper tools and algorithms able to exploit these computing facilities must be developed to efficiently and effectively process these large data volumes.

Further efforts are certainly needed for what concerns the implementation of the most critical steps characterizing the advanced DInSAR processing chains. This is particularly the case of the phase unwrapping (Ghiglia and Pritt 1998) and atmospheric noise filtering (Hanssen 2001) operations. In particular, an extensive research activity has been already carried out for the latter issue; this also includes possible integration with external information sources (GPS, radiosonde sensors, etc.) and rather sophisticated atmospheric models (Jolivet et al. 2012). However, in spite of such extensive research activities, a sufficient consensus on the final filtering solution is still missing and, probably, not easily reachable; this represents a drawback for a real standardisation of advanced DInSAR products or in case of surface deformation map generation immediately after a crisis event, such as a disruptive earthquake.

A final consideration is devoted to possible use of future SAR systems in geosynchronous or geostationary orbits (Ruiz Rodon et al. 2013). In this case, the satellite is placed in a geostationary orbit and the orbit jitter is used to form the synthetic aperture; the spread losses due to the increased satellite-Earth distance are compensated by increasing the integration time. Such systems, therefore, are characterised by a trade-off between integration time and resolution: for a typical X-band monostatic system embarked on a communication-like satellite, the trade-off can range, for instance, from about $100 \mathrm{~m}$ of resolution in $20 \mathrm{~min}$ to $5 \mathrm{~m}$ of resolution in $8 \mathrm{~h}$. More advanced configurations include the possibility to launch a swarm of several microsatellites, thus allowing a significant reduction of the integration time for a given ground resolution (Monti-Guarnieri et al. 2015). None of these systems is currently operational; it is clear that the implementation of such a new concept of observational radar could really boost up applications for emergency response and continuous monitoring. 
Acknowledgments The COSMO-SkyMed data were processed within the Italian Space Agency (ASI) contract n. I/044/09/0. The ERS-1/2 and ENVISAT data have been acquired through the Cat-1 proposal no. 6550 .

Open Access This article is distributed under the terms of the Creative Commons Attribution 4.0 International License (http:// creativecommons.org/licenses/by/4.0/), which permits unrestricted use, distribution, and reproduction in any medium, provided you give appropriate credit to the original author(s) and the source, provide a link to the Creative Commons license, and indicate if changes were made.

\section{References}

Arangio S, Calò F, Di Mauro M, Bonano M, Marsella M, Manunta M (2013) An application of the SBAS-DInSAR technique for the assessment of structural damage in the city of Rome, Struct Infrastruct Eng Maint, Manag Life-Cycle Des Perform:1-15

Badger L, Grance T, Patt Corner R, Voas J (2012) Cloud Computing Synopsis and Recommendations, NIST Special Publication 800-146. MD: National Institute of Standards and Technology, US. Department of Commerce, Gaithersburg

Berardino P, Fornaro G, Lanari R, Sansosti E (2002) A new algorithm for surface deformation monitoring based on small baseline differential SAR interferograms. IEEE Trans Geosci Remote Sens 40(11):2375-2383

Bonano M, Manunta M, Marsella M, Lanari R (2012) Long-term ERS/ENVISAT deformation time-series generation at full spatial resolution via the extended SBAS technique. Int J Remote Sens 33:4756-4783

Bonano M, Manunta M, Pepe A, Paglia L, Lanari R (2013) From previous C-Band to New X-Band SAR systems: assessment of the DInSAR mapping improvement for deformation time-series retrieval in urban areas. IEEE Trans Geosci Remote Sens 51(4):1973-1984

Burgmann R, Rosen PA, Fielding EJ (2000) Synthetic aperture radar interferometry to measure Earth's surface topography and its deformation. Annu Rev Earth Planet Sci 28:169-209

Casu F, Manzo M, Lanari R (2006) A quantitative assessment of the SBAS algorithm performance for surface deformation retrieval from DInSAR data. Remote Sens Environ 102(3-4):195-210

Casu F, Elefante S, Imperatore P, Zinno I, Manunta M, De Luca C, Lanari R (2014) SBAS-DInSAR parallel processing for deformation time-series computation. IEEE J Sel Top Appl Earth Obs Remote Sens 7(8):3285-3296

Chinnery MA (1961) The deformation of the ground around surface faults. Bull Seismol Soc Am 51:355-372

Covello F, Battazza F, Coletta A, Lopinto E, Fiorentino C, Pietranera L, Valentini G, Zoffoli S (2010) COSMO-SkyMed an existing opportunity for observing the earth. J Geodyn 49(3/4):171-180

Farr TG, Rosen P, Caro E, Crippen R, Duren R, Hensley S, Kobrick M, Paller M, Rodriguez E, Roth L, Seal D, Shaffer S, Shimada J, Umland J, Werner M, Oskin M, Burbank D, Alsdorf D (2007) The shuttle radar topography mission. Rev Geophys 2005:1-33

Farrell WE (1972) Deformation of the earth by surface loads. Rev Geophys 10(3):761-797

Ferretti A, Prati C, Rocca F (2001) Permanent scatterers in SAR interferometry. IEEE Trans Geosci Remote Sens 39(1):8-20

Franceschetti G, Lanari R (1999) Synthetic Aperture Radar Processing. CRC, Boca Raton

Gabriel AK, Goldstein RM, Zebker HA (1989) Mapping small elevation changes over large areas: differential interferometry. J Geophys Res 94(B7):9183-9191
Ghiglia DC, Pritt MD (1998) Two-dimensional phase unwrapping: theory, algorithms, and software. Wiley, London. ISBN 978-0471-24935-1

Guccione P (2006) Interferometry with ENVISAT wide swath scanSAR data. IEEE Geosci Remote Sens Lett 3(3):377-381. doi:10.1109/LGRS.2006.873876

Hanssen RF (2001) Radar interferometry. Data interpretation and error analysis. Springer, Netherlands. ISBN 978-0-7923-6945-5

Hsieh PA (1996) Deformation-induced changes in hydraulic head during ground-water withdrawal. Groundwater 34:1082-1089

Jolivet R, Agram PS, Lin NY, Simons M, Doin M-P, Peltzer G, Li Z (2012) Improving insar geodesy using global atmospheric models. J Geophys Res Solid Earth 119:2324-2341. doi:10. 1002/2013JB010588

Lanari R, Mora O, Manunta M, Mallorquí JJ, Berardino P, Sansosti E (2004) A small-baseline approach for investigating deformations on full-resolution differential sar interferograms. IEEE Trans Geosci Remote Sens 42(7):1377-1386

Lee CA, Gasster SD, Plaza A, Chang CI, Huang B (2011) Recent developments in high performance computing for remote sensing: a review. IEEE J Sel Top Appl Earth Obs Remote Sens 4(3):508-527

Manunta M, Marsella M, Zeni G, Sciotti M, Atzori S, Lanari R (2008) Two-scale surface deformation analysis using the SBASDInSAR technique: a case study of the city of Rome, Italy. Int J Remote Sens 29(6):1665-1684

Massonnet D, Feigl KL (1998) Radar interferometry and its application to changes in the earth's surface. Rev Geophys. 36:441-500

Massonnet D, Rossi M, Carmona C, Adragna F, Peltzer G, Feigl K, Rabaute $T$ (1993) The displacement field of the Landers earthquake mapped by radar interferometry. Nature 364(6433): $138-142$

Mogi K (1958) Relations between the eruptions of various volcanoes and the deformations of the ground surfaces around them. Bull Earthq Res Inst 36:99-134

Monti-Guarnieri A, Broquetas A, Recchia, A, Rocca F, Ruiz Rodon J (2015) Advanced radar geosynchronous observation systemARGOS. IEEE Geosci Remote Sens Lett 12(7):1406-1410

Mora O, Mallorquí JJ, Broquetas A (2003) Linear and nonlinear terrain deformation maps from a reduced set of interferometric SAR images. IEEE Trans Geosci Remote Sens 41(10): 2243-2253

O' Reilly MP, New BM (1982) Settlements above tunnels in the United Kingdom-their magnitude and prediction. Publ Inst Min Metall:173-181. (http://www.trid.trb.org)

Okada Y (1985) Surface deformation due to shear and tensile faults in a half-space. Bull Seismol Soc Am 75(4):1135-1154

Orr FM Jr (2009) $\mathrm{CO}_{2}$ capture and storage: are we ready? Energy Environ Sci 2:449-458. doi:10.1039/B822107N

Peltzer G, Rosen PA (1995) Surface displacement of the 17 May 1993 Eureka Valley earthquake observed by SAR interferometry. Science 268:1333-1336

Pepe A, Sansosti E, Berardino P, Lanari R (2005) On the generation of ERS/ENVISAT DInSAR time-series Via the SBAS technique. IEEE Geosci Remote Sens Lett 2(3):265-269

Rignot E (1998) Fast recession of a west Antarctic glacier. Science 281:549-551

Rosen P, Shams K, Gurrola E, George B, Knight D (2012) InSAR Scientific Computing Environment on the Cloud. AGU Conference San Francisco: 3-7

Ruiz Rodon J, Broquetas A, Monti Guarnieri A, Rocca F (2013) Geosynchronous SAR focusing with atmospheric phase screen retrieval and compensation. IEEE Trans Geosci Remote Sens 51:4397-4404 
Sadashiv N, Kumar SMD (2011) Cluster, grid and cloud computing: a detailed comparison. In: 6th International Conference on Computer Science and Education (ICCSE). pp 477-482

Sansosti E, Casu F, Manzo M, Lanari R (2010) Space-borne radar interferometry techniques for the generation of deformation time series: an advanced tool for earth's surface displacement analysis. Geophys Res Lett 37:L20305. doi:10.1029/2010GL044379

Sansosti E, Berardino P, Bonano M, Calò F, Castaldo R, Casu F, Manunta M, Manzo M, Pepe A, Pepe S, Solaro G, Tizzani P, Zeni G, Lanari R (2014) How second generation SAR systems are impacting the analysis of ground deformation. Int $\mathbf{J}$ Appl Earth Obs Geoinf 28:1-11. doi:10.1016/j.jag.2013.10.007

Shixiang CQCSM, Dade H (2004) Numerical simulation study of ground deformation in underground mining. Metal Mine (6):6-24

Stramondo S, Bozzano F, Marra F, Wegmuller U, Cinti FR, Moro M, Saroli M (2008) Subsidence induced by urbanisation in the city of Rome detected by advanced InSAR technique and geotechnical investigations. Remote Sens Environ 112:3160-3172. doi:10.1016/j.rse.2008.03.008
Torres R, Snoeij P, Geudtner D, Bibby D, Davidson M, Attema E, Potin P, Rommen B, Floury N, Brown M, Traver IN, Deghaye P, Duesmann B, Rosich B, Miranda N, Bruno C, L'Abbate M, Croci R, Pietropaolo A, Huchler M, Rostan F (2012) GMES Sentinel-1 mission. Remote Sens Environ 120:9-24

Werner C, Wegmueller U, Strozzi T, Wiesmann A (2003) Interferometric point target analysis for deformation mapping. In: Proc. of IGARSS, vol. 7, Toulouse, pp 4362-4364

Werninghaus R, Buckreuss S (2010) The TerraSAR-X mission and system design. IEEE Trans Geosci Remote Sens 48(2):606-614

Yerkes RF, Castle RO (1969) Surface deformation associated with oil and gas field operations in the United States. Land subsidence. http://www.pubs.rsc.org

Zebker HA, Villasenor J (1992) Decorrelation in interferometric radar echoes. IEEE Trans Geosci Remote Sens 30:950-959

Zeni G, Bonano M, Casu F, Manunta M, Manzo M, Marsella M, Pepe A, Lanari R (2011) Long-term deformation analysis of historical buildings through the advanced SBAS-DInSAR technique: the case study of the city of Rome, Italy. J Geophys Eng 8(3):S1S12 